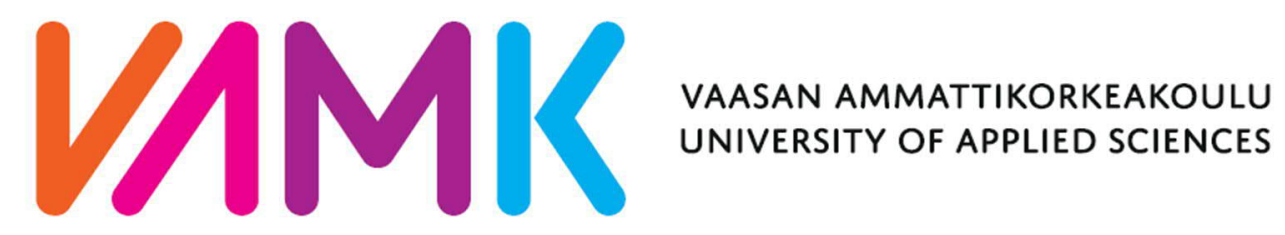

THIS IS AN ELECTRONIC REPRINT OF THE ORIGINAL ARTICLE

Please cite the original article:

Siemsen, S., Naaranoja, M. 2018. Learning System Development. In: Uden L., Liberona D., Ristvej J. (Eds.) Learning Technology for Education Challenges. LTEC 2018. Communications in Computer and Information Science, vol 870. Springer, Cham, 155-167.

https://doi.org/10.1007/978-3-319-95522-3 14

Version: Final draft

Copyright: @ 2018, Springer International Publishing AG, part of Springer Nature 


\title{
Learning system development
}

\section{A review of approaches to rethink learning in different contexts}

\author{
Sabine Siemsen ${ }^{1}$ and Marja Naaranoja ${ }^{2}$ \\ ${ }^{1}$ BKK Akademie Am Alten Feld 30, 36199 Rotenburg an der Fulda, Germany \\ \{ Siemsensabkk-akademie.de\} \\ ${ }^{2}$ Vaasa University of Applied sciences, Wolffintie 30, 65200 Vaasa, Finland \\ \{ marja.naaranoja@vamkfi\}
}

\begin{abstract}
Learning systems during last decades are about to transform from isolated and specific singular ego-systems [30] with closely defined and clearly measurable learning-inputs and - outputs into networked environments for guidance and innovation, to develop holistic competences and to create future as social development. Connecting interdisciplinary contexts, larger amounts of very heterogeneous learners from formerly independent cultural contexts and developments, and building on technology and digitalization, they become a specific cultural space and environment of their own [36]. Traditional learning-scenarios are called into question and new cultures of learning are formed. Also, boundaries between science and organizations weaken and dissolve. This paper pursues to use the potential of combining theories of learning and change, to analyze innovative learning-approaches, to separate the contrast of incremental (sustaining) versus disruptive innovations and to use examples from the contexts of academic, vocational and organizational learning-processes.
\end{abstract}

Keywords: Learning system 'Innovation $\cdot$ Learning technology $\cdot$ Learning Theories $\cdot$ Theories of Change $\cdot$ Learning-Scenarios $\cdot$ Multi-Stakeholder $\cdot$ Interdisciplinary learning environments $\cdot$ Learning in Networks $\cdot$ Learning Networks

\section{Introduction}

Learning systems are about to develop towards national or even global networked environments for learning-processes, using real life problems as motivational tasks and connecting heterogeneous stakeholder from various systems, aiming at the development of holistic and interdisciplinary competences to co-create knowledge and shape new cultures of learning. They become broader scope training programs, use new technologies and real-life business cases, and this breaks up former boundaries and generates a wider heterogeneity. Such learning environments provide a framework and a repertoire of conscious and unconscious practices, enable collaborative action, and shape

adfa, p. 1, 2011.

(c) Springer-Verlag Berlin Heidelberg 2011 
culture [2]. Consequently, this challenges traditional approaches, and transforms processes of learning and teaching. It requires workforce re-skilling and a re-definition of core-competences, a toolbox of digital and analog devices, and media literacy of all parties involved; it also needs to consider a theoretical framework which combines different angles of view on processes of learning and change.

This paper pursues to analyze which kind of skills and competences learners and teaching and supporting staff need to gain additional benefits from innovative learning scenarios. Therefore, it will use the potential of combining adequate theories of learning and change (section two), to discuss and analyze the role and pedagogical quality of technology and digital tools and the importance of collaboration and network (section three) to create innovative learning-approaches, which can be analyzed as being disruptive or incremental (section four). As boundaries between science and organizations will get weaker, section five will give a review on recent approaches of innovative learning scenarios in the contexts of academic, vocational and organizational learningprocesses. It will go into some of them in more detail, to separate and discuss the contrast of incremental (sustaining) versus disruptive innovations.

\section{Combining learning theories to reach emergent concepts}

To analyze different approaches as "new forms of education [...] beyond literacy and numeracy, to focus on learning environments and on new approaches to learning for greater justice, social equity and global solidarity" [38, p 3], it seems promising not to focus on singular theories, but to combine theories that look at these complex processes from different angles. Gregory Bateson's Learning Theory [1], George Siemens' Connectivism [32] and Otto Scharmer's Theory U [31] provide a framework which combines the implementation of cognitive processes of a raising awareness of contexts [1], a (not only technological) redesign of how we teach, learn and come to know [32] and modes of learning by sensing and actualizing emerging future possibilities [3]. Connecting these different ways to cope with learning and knowledge and heterogeneity, could lead to emergence and be of great value to discuss recent and find new strategies to turn (ego-) learning scenarios into (eco-) learning-systems.

All of the above listed theories brought about various forms of learning- scenarios, all of them aiming to innovate and enhance learning-settings, to include more contexts and stakeholder and to "activate our capacity to lean into the emerging future [to...] cultivate curiosity [and] compassion". Nevertheless, they emphasize or focus on different aspects of learning, use different lenses to look on learning-processes and the development of knowledge. Depending on the organization and their learning goals, the innovations concentrate on specific contexts of learning and generate different models of learning scenarios and -environments. So, for example MOCS are mainly used by universities, while CAPS (Community Awareness Platform Strategies) are examples for learning-scenarios which aim to develop strategies for political, economic, and social change [4]; U.Labs, which base on Otto Scharmer's Theory U focus on organizing global professional movements of consultants, change agents and educational actors, while in Living Labs (ENoLL n.d.), urban areas serve as technology-assisted research 
environments, where user co-create urban artifacts and local services. All of the mentioned examples can be seen as different stages of movements from isolated ego-systems of either academic research or vocational education towards learning-eco-systems, where stakeholder from all connected systems co-create strategies for innovation and trigger social-ecological transformation (compare [35]).

\section{The role of learning technology and digital tools for learning- environments}

The internet as an ubiquitous infrastructure for communication and coordination, multiplies the heterogeneity within learning-environments once again. It connects formerly independent developments of various cultural contexts, which now mutually reinforce, interdigitate and influence each other. Here, specific digital cultural spaces and environments emerge.

Digitalization offers plenty tools to connect learning communities situated in different local places, but also crucially change the environment where learning-processes take place. This raises the heterogeneity within the system and defines a new learning culture. Distance learning environments do not mean only literally locations. This paper defines environment: the composition of learning scenarios (traditional classroomlectures; various forms of blended-learning; e-Learning without presence sessions), forms (collaborative, cooperative and autonomous, individual learning), elements and tools constituting these different scenario (software, hardware, learningplatforms, social networks), and the heterogeneity of participants, here understood as the mix of different (learning) cultures.

MOOCS, CAPs, U.Labs and LivingLabs (see section two) are recent examples which re-think learning-environments, to "innovate and reinvent the existing model of online learning" (Scharmer 2014). They represent approaches of innovative learningsettings and -scenarios and implement a well-designed and reflected inclusion and combination of digital tools. The environment defines which tools, be them analogue or digital, will constitute additional benefits for both, learners and guiding teachers. According to Professor Jürgen Handke [11] they vary on a scale between mere augmentation of traditional settings and a complete virtualization, while it is of crucially importance to decide if and how to convert elements and actions of teaching into digital forms [11] - carefully and adapted to different affordances. Due to fast paced innovations in technological solutions, they are permanently changing and enhancing, and it is crucially important to see them as tools which serve to support and enhance learningscenarios and didactics - flexible and exchangeable - and not as a fixed solution itself.

In accordance with the above mentioned theories and their different angles of view, some "digital tools", like E-Portfolio, Weblogs, or LMS (Learning Management Platforms), focus on Didactics, and mere cognitive „solutions“, while others, like Agile Project Management, or SCRUM, or Design Thinking, focus on innovation, imagination and creativity. Blended (or Inverted) Scenarios are examples how scenarios can be re-thought, combining elements from analog and digital settings. The most important purpose of blended learning is, to offer opportunities for learners by using different 
methods to become self-sustaining, sustainable, and developing throughout life so that the present and future learning become more effective, more efficient, and more interesting [39].

As educational innovations, learning technologies offer new opportunities to learn, to generate and manage knowledge and abilities related to "real life problems". They can also be differentiated according to their referenciality, communality and algorithmicity [36]. While referenciality allows individuals to become an active (constitutive) part of a socially negotiated, established, and shared meaning based culture, specific forms of communality alter, adapt and transform them into new synthesis and emergence [36]. Algorithmicity transforms unmanageable crowds of data and information into forms and dimensions which can be handled by human perception. They make information accessible, create preconditions for a capacity to act and create new dependencies [36].

\subsection{Pedagogically good digital material}

In figure 2, criteria of pedagogically good digital material are presented, basing on empirical findings. The figure is based partly on the studies made by [29] and Reeves [26] and the thoughts of Naaranoja, Niemelä and Ilvesoksa [22]. The criteria can be traced also from the usability studies of Nielsen $[23,24]$ and the dimensions of the sense making of Jonassen $[17,18]$.

\section{Easy to learn and see the goal}

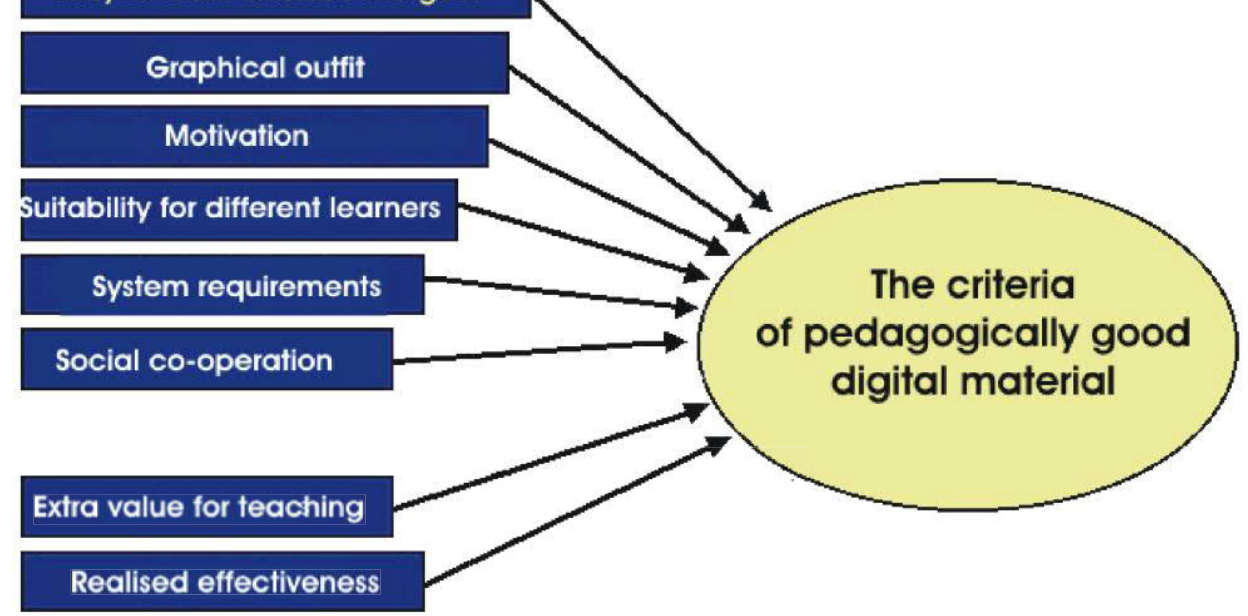

Fig. 1. The criteria of pedagogically good digital material.

The issues are not in an order of importance. However, one can claim that the easiness of seeing the goal and learning to use the environment are one of the most important 
criteria. Suitability for different learners mirrors the different learning styles of individuals and the different prerequisite knowledge levels. Digital material that takes care of social co-operation viewpoint contains for example 1) motivating the group behaviour, 2 ) engaging in the prepared learning environment, 3) supporting multimodal discussions [15]. The digital material of a course enables the student to take varied learning paths according to the skills of learners. Realized effectiveness of learning reveals the quality of the learning material. The digital material also provides extra value for teaching.

\subsection{Collaborative innovation management}

Successful innovation management in learning-scenarios requires teamwork and creative learning as well as transcultural strategies of knowledge creation in all fields of education, professional praxis, collective learning and development. It bases on digital media and networking strategies and challenges not only students but also the teaching (and learning) staff. There are still many challenges in creating the digital learning environments. Some of the challenges have to do with pedagogical implementation, technical support, and teachers' increased workload, and some with low budget. A joint development of learning technology environment is important since [11]:

- It is waste of time to produce similar materials all over the world. This is especially important for small countries like Finland and Germany.

- Joint efforts can lead to better start ups with greater resources, both financial and knowledge

- Pedagogical implementation can be improved by using the vast experience into consideration already in early phases

- The workload can be divided

- Knowledge management can be improved by co-operation between multi-stakeholders, like teachers, researchers and vocational- or field-experts

- Co-operation between business line and educational institutes is improved simultaneously

- Technical innovations may be utilized in a larger scale.

The most crucial aspect in regard to effectiveness is that the digital material should support the evolving of the co-operation skills. Co-operation is needed also to support the learning process. At this point it can be helpful to develop the competence to see problems from different angles.

Reviewing literature on recent approaches, we did not yet find any open access teaching material that is built on the idea to utilize team-based learning.

The literature recognizes the following type of teaching staff collaboration methods: Agreeing how to approach the issue from different angles (e.g. Inter-disciplinary teaching strategies for mental health law [14], joint observation [21], using students in teaching team [27], parents helping to learn [3], project based learning support [28] and distance learning supporting team [9].The important factors in teaching teams are the right collection of expertise, team work ability and enough time for team to collaborate. 


\section{$4 \quad$ Efficient and sustainable learning innovations}

\subsection{The learning system innovations}

Technology based innovation during last decades have been mostly linked with digitalization. Various forms and models of MOOCs like xMOOCs (Augmentation - see [12]), cMOOCs (following Connectivism, see [34], but also numerous combinations and variations (compare [33] and [34]) as well as digital learning platforms and digital games are examples of technology based innovations. The less talked innovations that require technology might be laboratory tasks where a more developed system is constructed in order to give the learners a possibility to understand a complex environment, or to simulate real business tasks. To make technology-based innovation efficient and sustaining requires not only an understanding of how to use technology, but also of the context(s) of the learned issue, and of the herewith connected and therefore required process of learning.

When we pursue to link the business in education it is important to understand the business case but also to understand the process of learning. When we use real life challenge in education, the challenges are even larger, as companies not only need to know the students' ability to work, but also have to know how to motivate the students to find data, to learn skills and to develop competences. In all the above cases, one single person is seldom a virtuous in all the required areas. Especially talking about complex tasks and activities, requires various experts, like topic-experts to help students to solve the given problems and to acquire the needed theoretical knowledge, and communication-experts to teach the students how to communicate the results for the companies.

\subsection{Disruptive versus incremental (sustaining) innovations}

Donaldson [7] differentiates between innovations being sustaining, and innovations being disruptive. While sustaining innovations base on existing approaches and/or models, and try to improve those, disruptive innovations do not aim to improve something, but represent innovating system of its own and - at least in the beginning - often are just easier to handle, more cost-efficient, and often even of lower quality than established ones. But due to an easier usability and lower costs they sometimes succeed to improve and then to reach a quality on a higher level than those of the systems being or becoming dispersed. But on the other hand, if such disruptive innovations are not able to reach a high quality fast enough they run into danger to be »absorbed « by the traditional systems which hinder the innovation to be-come disruptive, by integrating it in the existing system. Many approaches of Online- Settings and E-Learning-Scenarios are examples of changing possible disruptive approaches into sustaining, respectively incremental innovations, when organizations use technological tools, to improve their teaching- and learning-settings, to reach more and/or new customers (compare Siemsen [34]).

Although innovation sometimes involves a discontinuous shift, most of the time it takes place in an incremental mode, often used in quality development. As disruptive 
or new-to-the-world innovations are only $6-10 \%$ of all innovations projects, the contribution shows, how cumulative gains in efficiency can be much greater over time than the ones based on singular or occasional radical changes [37]. The contributions show, how disruptive innovations like MOOCS don't catch on with mainstream users until quality catches up to their standards [5]. All of the above listed examples of innovative learning settings and scenarios (MOOCS, CAPs, U.Labs, LivingLabs) support visioncreation and planning, the increase of access, and mutual learning of stakeholders [19], but they use different ways (basing on the learning-theory they are connected with) and different angles of view to re-think learning-environments, to "innovate and reinvent the existing model of online learning" [30].

Therefore, educational innovations in the digital age will be discussed according to the specific qualities of disruptive and incremental innovations (like the use of technology, their linking of different contexts/stakeholder, their learning design, or their method of measuring/defining success) used in education. Table 1 can be used to discuss and compare them to each other.

Table 1. The learning system innovation may be either disruptive or incremental

\begin{tabular}{|l|l|l|}
\hline & Disruptive innovation & Incremental innovation \\
\hline $\begin{array}{l}\text { Technology based } \\
\text { innovation }\end{array}$ & MOOC & $\begin{array}{l}\text { Sharing knowledge in learn- } \\
\text { ing platforms } \\
\text { Learning Games } \\
\text { Inverted-/Flipped Classroom } \\
\text { Scenario }\end{array}$ \\
\hline $\begin{array}{l}\text { Linking business in } \\
\text { education }\end{array}$ & $\begin{array}{l}\text { Real life business challenge } \\
\text { in education }\end{array}$ & $\begin{array}{l}\text { Use of business case in edu- } \\
\text { cation } \\
\text { Shift from input/output ori- } \\
\text { entation to throughputs }\end{array}$ \\
\hline Learning Setting/Scenarios & $\begin{array}{l}\text { Completely virtualized sce- } \\
\text { narios }\end{array}$ & $\begin{array}{l}\text { Blended Learning; Inverted } \\
\text { Settings }\end{array}$ \\
\hline $\begin{array}{l}\text { Assessment/Testing/ } \\
\text { Measuring Results }\end{array}$ & $\begin{array}{l}\text { Competence Fields instead } \\
\text { of measurable criteria }\end{array}$ & $\begin{array}{l}\text { Shift focus from input-/out- } \\
\text { put-orientation to through- } \\
\text { puts (from ... to process) }\end{array}$ \\
\hline
\end{tabular}

\section{$5 \quad$ Examples of current digital learning programs and -scenarios}

There are plenty of learning programs that EU has been funding and many of the results are publicly available. The following examples show efforts on different levels and from different contexts to develop the skills of teachers and share stories of successful use of new technologies. In Section 5.4 some of them will be described in more details to explain their analytical correlation to the above table. 


\subsection{Examples of learning for children}

We have selected four different kind of learning programs to represent information technology use in learning.

- The MENTEP' (MENtoring Technology-Enhanced Pedagogy 2015 - 2018) "project addresses the need in Europe for teachers able to innovate using ICT in their classroom and for improved data on teachers' digital competence. Based on this premise, MENTEP investigates the potential of an online self-assessment tool to empower teachers to progress in their Technology-Enhanced Teaching (TET) competence at their own pace." [20]

- The eTwinning ${ }^{2}$ action was launched in January 2005. Nowadays, eTwinning offers a platform for staff (teachers, head teachers, librarians, etc.), working in a school in one of the European countries involved, to communicate, collaborate, develop projects, share and, in short, feel and be part of the most exciting learning community in Europe. [8]

- Innovative Technologies for Engaging Classrooms, iTech ${ }^{3}$ 2011-2014 [16] main results were a scalable scenario-led design process for developing digital pedagogy; the Future Classroom Toolkit and accompanying training provision; an extensive library of Future Classroom Scenarios, Learning Activities and Learning Stories Living Schools $\mathrm{Lab}^{4}$ that is open to be used by everybody.

- There are digital learning games for children in the internet done by companies 5 .

\subsection{Context University}

Universities all over the world innovate the learning material development. The list represents some types of development efforts in Finland and Germany:

- Finnish applied science universities have created open society named DIGMA ${ }^{6}$ where everybody is able to use and further develop the joint learning material [6].

- real life business cases are used in Finland e.g. in the Kykylaakso Bio-Hub ${ }^{7}$ at Applied Science University of Tampere, where the students have started companies and collaborate with several companies and authorities.

- at Vaasa University of Applied Sciences and Novia have collaboratively organized so called tandem ${ }^{8}$ teaching where the Swedish speaking students learn Finnish and Finnish speaking students learn Swedish. This can be seen as a teaching method where the focus has shifted from input-/output-orientation to throughputs. Tandem,

\footnotetext{
${ }^{1} \mathrm{http} / /$ mentep.eun.org/

${ }^{2}$ https://www.etwinning.net/en/pub/index.htm

${ }^{3} \mathrm{http}: / /$ itec.eun.org/web/guest/home

${ }^{4} \mathrm{http}: / / 1$ sl.eun.org

${ }^{5} \mathrm{http} / / /$ www.oppijailo.fi/lapset_ja_nuoret

${ }^{6} \mathrm{https}: / /$ moodle.amk.fi/

${ }^{7} \mathrm{http} / / /$ tamk-blogi.tamk.fi/tehokas-ja-kaytonnonlaheinen-bptn-kulttuurikylpy/

${ }^{8} \mathrm{http} / / /$ www.puv.fi/fi/study/news/korkeakoulutandemilla_kieli_haltuun/
} 
as a method for learning languages, was first used in Germany and France in 1963. Tandem language learning have in common is the fact that there are people with different native languages who cooperate according to the principles of reciprocity and autonomy.

- in Germany, the Philipps University is a traditional "brick and mortar" university where Jürgen Handke, Professor of English and Computational Linguistics, developed and implemented the Virtual Linguistics Campus (VLC) ${ }^{9}$, the world's largest e-learning platform for linguistics and his "Inverted Classroom Mastery Model" [11]

- oncampus, a subsidiary company of the Fachhochschule Lübeck, Germany, took further steps by not only developing solutions to implement digitalization into their offers for their "traditional" students but also a completely virtualized "World of Learning" 10 for their students as well as for different other target-groups.

\subsection{Context vocational and organizational learning}

Vocational and organizational learning all over the world is pursuing to improve the learning methods in order to make learning agile and efficient. The list represents some types of development efforts in Finland and Germany:

- the BKK Akademie11 in Rotenburg, Germany is the corporate educational institution for apprenticeship, and corporate vocational learning programs for the (recently roundabout 80) company-health-insurance-funds in Germany (in German BKK is BetriebsKrankenKasse). Recently they are about to redesign their concept of apprenticeship, and corporate vocational learning programs, by employing an educational scientist, to re-think, re-develop, conduct and evaluate a future-oriented and sustainable learning concept seen from a perspective of lifelong learning, a raising heterogeneity and digitalization.

- use of a mobile application in Finnish and German vocational schools has supported the idea that mobile learning supports workplace learning (Virnes et al 2017)

- in Finland there is a Business mentors association ${ }^{12}$ which organizes voluntary persons, business mentor who are willing to share their expertise and experiences with new or old entrepreneurs.

- Yleisradio Ltd., the Finnish broadcasting company organizes different kinds ${ }^{13}$ of blended learning activities especially collective learning activities annually. The purpose of these activities is to enhance adoption of a more multimedia- and user-centered mindset within the organization. They use different kinds of pedagogical practices in these learning events, such as group discussions, artefacts, stories, coaching and user testing, the purpose of which was to build the participants' capability to plan multimedia projects and develop their expertise. The practices and artefacts of

\footnotetext{
${ }^{9} \mathrm{http}$ ///inguistics.online.uni-marburg.de/qualify/certified_courses_direct.html

${ }^{10} \mathrm{https}: / /$ www.oncampus.de/

${ }^{11} \mathrm{https}: / /$ www.bkk-akademie.de/

$12 \mathrm{http}: / / \mathrm{www} \cdot$ botniamentors.fi/briefly-in-english

13 https://yle.fi/aihe/artikkeli/2017/08/28/yle-perustaa-journalismin-akatemian-ja-vahvistaa-tutkivaa-journalismia)
} 
the agile teams together constructed the epistemic culture and knowledge construction system of the domain.)

\subsection{Analyzing approaches in regard to being disruptive or sustaining innovations}

Table 1 can be helpful to discuss and analyze approaches of innovative learningsetting. This will be shown, using examples of the above listed approaches:

\section{The Learning Platform World of Learning ${ }^{14}$.}

In regard to the technology based innovation, oncampus can be described as disruptive development, it changed the idea of eLearning as additional offers into a completely virtualized version of MOOCs which vary on a scale between free courses and courses liable to pay costs. This is also a disruptive-innovative way to link business in education, bringing together learner and trainer from various stakeholders and organizations and using completely virtualized scenarios. Also, the Assessment and Testing is a disruptive development, ranging from badges and training certificates up to Bachelor- and Master-study-degrees and offering different solutions for a large scale of learning-processes and interests.

The BKK Akademie in Rotenburg/Fulda, Germany ${ }^{15}$ : Re-thinking apprenticeship and vocational learning and corporate vocational learning programs

The idea of changing the concept of learning-offers by including elements of eLearning, offering digital tools to support self-organized learning and to switch scenarios towards blended- and inverted settings is an incremental innovation which includes the experiences of different learning places (in Germany apprenticeships take place partly in the organizations, partly at vocational schools, and for the apprentices of company health insurance funds additionally at the BKK Akadmie as corporate educational institution). Re-thinking and redesigning the concept of education not as an "inhousesolution" but by including theories and the experience from educational science by employing an educational scientist from "outside the system", to build networks with other organizations (from academic and from vocational systems) can be described as a disruptive innovation which links educational science with business, and which aims to develop and evaluate new holistic methods of learning, teaching and testing for a target group with a raising heterogeneity and permanently changing learning-demands (in regard to content, but also to methods and competences).

\section{Teaching language in Finnish Universities}

The idea of teaching Swedish or Finnish by making the students to teach each other is disruptive at applied science university context while a student is able to be at the same time master of his/her own mother tongue but then on the other hand learner in

\footnotetext{
${ }^{14} \mathrm{https}: / /$ www.oncampus.de/
}

15 https://www.bkk-akademie.de/ 
the other language and in addition is able to learn at the same time some general concepts when talking about his/her own subject field to somebody who comes from another field. Though the method has been used earlier when teaching exchange students the use in applied science university is disruptive.

The collaborative learning material creation at the best is incremental when large working groups share the learning material and the given resources are small. The totally new way of teaching in large teacher teams from many different universities might be difficult.

\section{Finnish Vocational/Organizational Context.}

The company based teaching scenarios can be disruptive development when the new networking with other learning organization give new ideas for the company development. The vocational schools in Finland are fighting with too little resources and this has created challenge to develop new ideas but in this kind of setting it is challenging to be more than incrementally innovative.

\section{Conclusions}

Joint efforts provide a possibility to develop network-based learning-environments, -scenarios, and material. The consortiums motivate and encourage to continue the efforts, though a sound digital material is a challenge and the link between material and the use of it is only a part of the challenge. The other challenges are in creating well modified projects to support a highly heterogeneous group of learners in institutions and organizations with different teaching goals and to support the learning of different disciplines.

The current strategies of building up more and more complex learning contents with business-based problems need even more collaboration with teachers and scientists and new types of strategies to develop these learning-eco-systems where stakeholders from all connected systems co-create strategies for innovation and trigger social-ecological transformation.

We need more research on the collaborative, multidisciplinary teacher and student teams that teach and learn in different settings. The teaching team needs to learn to share knowledge and create joint programs that supports project and research-based learning.

\section{References}

1. Bateson, G. (1972). The logical categories of learning and communication. Steps to an Ecology of Mind, 279-308.

2. Becker, L./Montiel Alafont, F. J. (2015): Warum in interkulturellen Projekten das wahre Leben tobt; in: Becker, L./Gora, W./Wagner, R. (2015): Erfolgreiches Interkulturelles Projektmanagement, Düsseldorf (Symposion)

3. Business mentors (2018) http://www.botniamentors.fi/briefly-in-english Accessed 16.3.2018 
4. Buick, D. (2016) Interdisciplinary Team Teaching to Support Twenty-First Century Learning Skills. Journal of Initial Teacher Inquiry, 2, p.28.

5. CAPS Initiative (2017): Collective Awareness Platforms for Sustainability and Social Innovation. Hg. v. European Commission. Online verfügbar unter https://ec.europa.eu/digitalsingle-market/en/collective-awareness, zuletzt geprüft am 09.03.2017.

6. Christensen, C. M., Raynor, M. E., \& McDonald, R. (2015). What is Disruptive Innovation. Harvard Business Review, 93(12), 44-53.

7. DIGMA (2017) Open digital material. Accessed 30.12.2017. https://moodle.amk.fi/?lang=en

8. Donaldson, Jonan (2013): Massively open. How massive open online courses changed the world. [North Charleston, South Carolina]: [CreateSpace Independent Publishing Platform].

9. eTwinning (2017): eTwinning platform. Accessed 30.12.2017. https://www.etwinning.net/en/ pub/index.htm

10. Gibbs, G.R. and White, S., 2014. Going the distance: supporting a teaching team to move to distance learning. A Case Study. How ready are academics for the 'Only Connect'world?

11. Joachim Grzega \& Marion Schöner (2008) The didactic model LdL (Lernen durch Lehren) as a way of preparing students for communication in a knowledge society, Journal of Education for Teaching, 34:3, 167-175, DOI: 10.1080/02607470802212157

12. Handke, Jürgen (2014): Patient Hochschullehre. Vorschläge für eine zeitgemäße Lehre im 21. Jahrhundert. Tectum Verlag Marburg.

13. Handke, Jürgen (2015): Handbuch Hochschullehre Digital. Leitfaden für eine moderne und mediengerechte Lehre. Tecum Verlag Marburg.

14. Handke, Jürgen (2016): Konstruktive Disruption statt Evolution. https://www.youtube.com/watch?v=b7Eg_7jD_6M

15. Hanson, L., Fitzpatrick, R. \& Abo-El Ella, S.(2015) Inter-disciplinary teaching strategies for mental health law. International journal of law and psychiatry, 39, pp.1-5.

16. Hauan, N. P. (2017). Learning science in interactive exhibitions. Frameworks for design and evaluation of material for exploratory learning experiences. doctoral dissertation, Accessed 21.3.2018, http://hdl.handle.net/1956/15590

17. iTech (2017): Innovative Technologies for Engaging Classrooms. Accessed 30.12.2017. http://itec.eun.org/web/guest/about

18. Jonassen, D. H. 1995. Supporting Communities of Learners with Technology: a Vision for Integrating Technology with Learning in Schools. Educational Technology July-August 1995, pp.60-63

19. Jonassen, D. H. \& Land, S. M. (ed.) 2000. Theoretical Foundations of Learning Environments. New Jersey: Lawrence Erlbaum Associates

20. Silvo, I. (2018), Journalismiakatemia https://yle.fi/aihe/artikkeli/2017/08/28/yle-perustaajournalismin-akatemian-ja-vahvistaa-tutkivaa-journalismia, Accessed 10.3.2018

21. Juujärvi and Pesso (2013) Actor Roles in an Urban Living Lab: What Can We Learn from Suurpelto, Finland? Technology Innovation Management Review

22. Learn and enjoy (2018) http://www.oppijailo.fi/lapset_ja_nuoret, Accessed 20.3.2018

23. MENTEP (2017), MENtoring Technology-Enhanced Pedagogy. http://mentep.eun.org/home Accessed 30.12.2017

24. Mtika, P., Robson, D. \& Fitzpatrick, R. (2014) Joint observation of student teaching and related tripartite dialogue during field experience: Partner perspectives. Teaching and teacher education, 39, pp.66-76.

25. Naaranoja, M., Niemelä, R., Ilvesoksa, O., 2002. Lessons from the development of computer based learning environment in Finland, BEAR conference (unpublished paper)

26. Nielsen, J. 1995. Advances in HCI vol. 5. Intellect Publishers. 
27. Nielsen, J. 1993. Usability Engineering. New York: Academic Press

28. Nokelainen, P., Tirri, H., 2002. in Verkko-opetuksen sisältötuotanto osatutkimuksen tilanne, http://dll.hamk.fi/dl/dl1/index.html accessed on 29.10.2002

29. Reeves, T. ,1994. Evaluating What Really Matters in Computer-Based Education [http://www.educationau.edu.au/archives/cp/reeves.htm]

30. Rosenfeld, B., 2015. Team teaching buddies: Student teaching in the era of edTPA [http://digitalcommons.uconn.edu/cgi/viewcontent.cgi?article=1003\&context=nera_2014]

31. Ruggiero, D. \& Boehm, J.D. (2017) Project-based learning in a virtual internship programme: A study of the interrelated roles between intern, mentor and client. Computers \& Education, 110, pp.116-126.

32. Saarinen ,J. , 2002. Verkko-opetuksen sisältötuotanto osatutkimuksen tilanne, http://dll.hamk.fi/dl/dl1/index.html, accessed on 29.10.2002

33. Scharmer, Claus Otto; Käufer, Katrin (2013): Leading from the emerging future. From egosystem to eco-system economies. 1. ed. San Francisco, Calif.: Berrett-Koehler (A BK currents book).

34. Scharmer, Otto (2014): A Global Action Leadership School in the Making. In: The Huffington-Post 26.03.14. Online: http://www.huffingtonpost.com/otto-scharmer/reordering-fromwithin_b_5038368.html

35. Siemens, George (2007): Connectivism. Learning conceptualized through the lens of today's world. Online verfügbar unter http://www.elearnspace.org/presentations/connectivism_online_OCC2007.ppt, zuletzt geprüft am 09.02.2014.

36. Siemsen, S., \& Jansen (2014): Connectivism and Interactionism Reloaded: Knowledge Networks in the Cloud: A Theoretical Approach to a Shift in Learn-ing through Connectivism and MOOCs. In L. Uden (Ed.), Learning technology for education in cloud: MOOC and big data : third International Workshop, LTEC 2014, Santiago, Chile, September 2-5, 2014. Proceedings (pp. 1-12, Communications in Computer and Information Science, Vol. 446).

37. Siemsen, Sabine (2015): Learning, Knowledge and Competence in Global Online-Universities: How Terminology Shapes Thinking. In: Lorna Uden, Dario Liberona und Tatjana Welzer (Hg.): Learning technology for education in cloud. 4th International Workshop, LTEC 2015, Maribor, Slovenia, August 24-28, 2015, Proceedings. Cham: Springer (Communications in Computer and Information Science, 533), S. $28-42$.

38. Siemsen, Sabine (upcoming 2018): Universities in the Present Age. In: Tagungsband DGFE 10 Internationale Jahrestagung "Organisation und Netzwerke". Universität Hildesheim.

39. Stalder, Felix (2016): Kultur der Digitalität, Suhrkamp Verlag, Berlin

40. Tidd, J \& Bessant, J. (2009). Managing Innovation: Integrating technological, market and organizational change. 4th Ed. Chishester: Wiley

41. UNESCO (2015): Rethinking education. Towards a global common good? Paris: UNESCO Publishing. Online: http://unesdoc.unesco.org/images/0023/002325/232555e.pdf. Last access 21.10 .2017

42. Wahyuningsih, S., Satyananda, D., \& Ghosh, A. (2018). Implementation of Blended Learning Innovation in Graph Theory Application Course to Face the Education Challenge in the 21 st Century.

43. Salmela E. (2014) Korkeakoulutandemilla kieli haltuun, http://www.puv.fi/fi/ study/news/korkeakoulutandemilla_kieli_haltuun/accessed on 12.1.2018

44. Weber, Susanne (2004): Organisationsnetzwerke und pädagogische Temporärorganisation. In: Böttcher, Wolfgang; Terhart, Ewald (Hrsg.): Organisationstheorie in pädagogischen Feldern - Analyse und Gestaltung. Wiesbaden: VS Verlag für Sozialwissenschaften. S. 253269. 